\title{
Metarhizium alvesii sp. nov.: A new member of the Metarhizium anisopliae species complex
}

\author{
Rogerio B. Lopes ${ }^{a}$, Daniela A. Souza ${ }^{a}$, Luiz F.N. Rocha ${ }^{\mathrm{b}, \mathrm{c}}$, Cristian Montalva ${ }^{\mathrm{d}}$, Christian Luz ${ }^{\mathrm{c}}$, \\ Richard A. Humber ${ }^{\mathrm{e}}$, Marcos Faria ${ }^{\mathrm{a}, *}$ \\ ${ }^{a}$ Embrapa Genetic Resources and Biotechnology, CP 02372, Brasília, DF 70770-917, Brazil \\ ${ }^{\mathrm{b}}$ Instituto Federal de Educação, Ciência e Tecnologia de Goiás, Aparecida de Goiânia, GO 74968-755, Brazil \\ ${ }^{\mathrm{c}}$ Instituto de Patologia Tropical e Saúde Pública, Universidade Federal de Goiás, Goiânia, GO 74690-900, Brazil \\ d Instituto de Bioquímica y Microbiología, Facultad de Ciencias, Casilla 567, Universidad Austral de Chile, Valdivia 5090000, Chile \\ e USDA-ARS Emerging Pests and Pathogens Research Unit, Robert W. Holley Center for Agriculture and Health, Ithaca, NY 14853, USA
}

\section{A R T I C L E I N F O}

\section{Keywords:}

Ascomycota

Clavicipitaceae

Entomopathogenic fungi

Taxonomy

Multilocus phylogeny

\begin{abstract}
A B S T R A C T
A strain within the Metarhizium anisopliae species complex was isolated in 2009 from a soil sample in a banana plantation in the municipality of Quixeré, Northeastern region of Brazil. Previous studies showed that this insectpathogenic strain does not fit with any current taxon within the M. anisopliae species complex, as determined by both genomic and by mass spectrometric analyses. In the present study, CG1123 (=ARSEF 13308) is shown to be morphologically indistinguishable from most species in this cosmopolitan species complex, whereas multilocus phylogeny confirmed its uniqueness and supports its recognition as a new species, Metarhizium alvesii, in honor of Sérgio Batista Alves, one of the founders of insect pathology in Brazil.
\end{abstract}

\section{Introduction}

The genus Metarhizium Sorokin (Hypocreales: Clavicipitaceae) includes well-known entomopathogenic fungi that serve as the active ingredients of over 60 commercial mycoinsecticides worldwide (Faria and Wraight, 2007). Multilocus phylogenetic analyses have clarified relationships within this genus and, although morphological differences are not always evident among species, well-justified proposals of new taxa have been made (Bischoff et al., 2009; Kepler et al., 2014; Montalva et al., 2016). Recent taxonomic refinements that focused on the cryptic diversity within the $M$. anisopliae species complex using multigene phylogeny have, so far, recognized 10 species in this group (Bischoff et al., 2009; Kepler et al., 2014).

With the exceptions of $M$. globosum, M. guizhouense, and $M$. indigoticum, the remaining species currently treated within the $M$. anisopliae species complex are noted to occur in Brazil: M. anisopliae sensu stricto (Faria et al., 2009; Rocha et al., 2013; Lopes et al., 2013b, 2014; Rezende et al., 2015), M. pingshaense (Xavier-Santos et al., 2011; Lopes et al., 2014), M. robertsii (Bischoff et al., 2009; Xavier-Santos et al., 2011; Rocha et al., 2013; Lopes et al., 2013b, 2014; Rezende et al., 2015), M. brunneum (Lopes et al., 2012, 2014), M. lepidiotae (Lopes et al., 2013b, 2014), and M. acridum (Magalhães et al., 1997; Driver et al., 2000; Lopes et al., 2014). Additionally, two taxonomically unassigned lineages within the $M$. anisopliae species complex have been reported (Rocha et al., 2013; Rezende et al., 2015). To our knowledge, other four Metarhizium species are known from Brazil: M. pemphigi (Rocha et al., 2013) and M. blattodeae (Montalva et al., 2016) from the M. flavoviride species complex; and M. brasiliense (Kepler et al., 2014), which is closely related to $M$. album, previously treated as $M$. flavoviride “Type E" by Driver et al. (2000). Finally, one of Brazil's most prominent fungal entomopathogens has been regarded to be Metarhizium ( $=\mathrm{No}$ muraea) rileyi (Alves et al., 1978; Sujii et al., 2002).

One single Metarhizium sp. strain, CG1123, with no clear genomic relationship to any described species within the $M$. anisopliae species complex was obtained at a site located in a tropical zone with dry summer, according to Köppen's climate classification system (Alvares et al., 2013). The previous work also both confirmed the pathogenicity of this strain for the banana weevil Cosmopolites sordidus (Germar) (Coleoptera: Curculionidae) and provided a preliminary genomic assessment (Lopes et al., 2013a). A complementary study using mass spectrometry analyses confirmed the uniqueness of this strain as distinct from any other described species of Metarhizium (Lopes et al., 2014). In the present study, we characterized the morphology of CG1123 and conducted more extensive multigenic phylogenetic evaluations with this strain in order to evaluate whether this taxon should be recognized as a new species.

\footnotetext{
* Corresponding author.

E-mail address: marcos.faria@embrapa.br (M. Faria).
} 


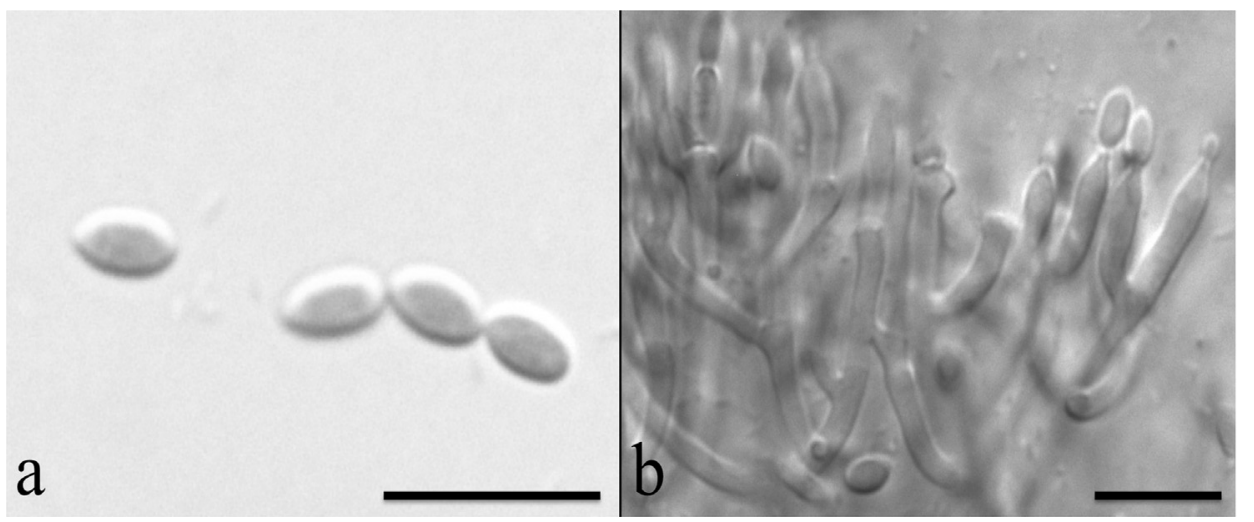

Fig. 1. Conidiogenous cells and conidia of Metarhizium alvesii. a. Conidia; b. Phialides with developing conidia. Bar $=10 \mu \mathrm{m}$.

\section{Materials and methods}

\subsection{Field location, collecting and processing of material}

Strain CG1123 was found in February 2009 in an intensively cultivated banana plantation in the municipality of Quixeré, Ceará state, Northeastern Brazil (Lopes et al., 2013a). It was isolated from a soil sample and maintained as a monosporic culture. Partial sequences of the genes $\beta$-tubulin (BTUB), RNA polymerase II largest subunit (RPB1), RNA polymerase II second largest subunit (RPB2) and translation elongation factor 1 -alpha ( $3^{\prime}$ end of the TEF-1 $\alpha$ ) were deposited in the GenBank under the accession numbers KY007611, KY007612, KY007613, and KY007614, respectively.

\subsection{Morphological evaluations}

This strain was investigated based on morphological characteristics, and semi-permanent slide mounts were prepared in lactophenol-cotton blue. The strain was grown on quarter-strength Sabouraud dextrose agar + yeast extract (SDAY/4: $2.5 \mathrm{gL}^{-1}$ peptone, $10 \mathrm{gL}^{-1}$ dextrose, $2.5 \mathrm{~g} \mathrm{~L}^{-1}$ yeast extract, $20 \mathrm{~g} \mathrm{~L}^{-1}$ agar) for 5-7 days in the dark at $25 \pm 1{ }^{\circ} \mathrm{C}$. Fungal microstructures (conidiophores, conidiogenous cells, and conidia) were examined by brightfield or phase contrast microscopy (Nikon Eclipse E600), documented with a Nikon DS-Fi1 digital camera, and measured with Motic Images Plus 2.0 software. Measurements were based on 50 objects per microstructure from which we calculated mean values, standard error of the mean ( \pm SEM). The color of the conidial mass was determined using the Pantone color system (Eiseman and Herbert, 1990) as well a close approximation of this color for a computer monitor using the values of the CMYK (Cyan, Magenta, Yellow, black) color system and an adjustment for color opacity.

\subsection{Molecular characterization}

Strain CG1123 was grown in $150 \mathrm{~mL}$ on quarter strength SDY broth (SDY/4; $2.5 \mathrm{~g}$ bacto peptone, $10 \mathrm{~g}$ dextrose, $2.5 \mathrm{~g}$ yeast extract) for 7 days in a shaker at $125 \mathrm{rpm}$ and $25 \pm 1{ }^{\circ} \mathrm{C}$. Hyphae and conidia were harvested, dried, and ground into a powder in liquid nitrogen with a mortar and pestle. A SDS (sodium dodecyl sulfate)-based method described by Raeder and Broda (1985) was adopted for DNA extraction. Partial sequences of the following four genes were amplified by polymerase chain reaction (PCR): BTUB using the primers BT1F and BT1R (Bischoff et al., 2009); RPB1 with RPB1C and RPB1Af (Stiller and Hall, 1997); RPB2 with fRPB2-5F and RPB2-7cR (Liu et al., 1999); and 3' end of the TEF-1 $\alpha$ with primers $983 \mathrm{~F}$ and 2218R (Rehner and Buckley, 2005). The $5^{\prime}$ end of TEF- $1 \alpha$ was previously sequenced by Lopes et al. (2013a). The PCR products were checked using agarose gel electrophoresis and sent for purification and sequencing by Helixxa Genomic Services (Paulínia, SP, Brazil). Both strands of the PCR products were sequenced using the Applied Biosystems Big Dye v.3.1 kit and the same primers described above with an ABI 3500 automatic sequencer. Contigs of CG1123 sequence data were assembled using Chromas Pro (V. 1.5, Technelysium Pty Ltd). Reference sequences were obtained from GenBank and are listed in Table 1 (see Supplementary Material). Multiple sequence alignments of each gene were made with Mega 5.0 .3 by ClustalW and manually adjusted. The program jModelTest 0.1.1 (Posada, 2008) was used to identify the best-fit models of nucleotide substitutions using the corrected Akaike information criteria. A concatenated alignment (3'TEF, 5'TEF, RPB1, RPB2 and BTUB) was generated with Mesquite 3.04 software (Maddison and Maddison, 2015). Analyses of the consensus sequences of each single gene and the concatenated alignment were carried out under the Maximum Parsimony (MP) method, and bootstrap support (BS) values were provided. Additionally, we used Bayesian phylogenetic inference by MrBayes v. 3.2.1 (Ronquist et al., 2012), and BS values were included in the Bayesian trees. Analysis was run over ten million generations, with tree sampling every 100 generations; the first $25 \%$ of trees were discarded prior to consensus tree calculation.

\section{Results}

\subsection{Taxonomy}

Metarhizium alvesii Lopes, Faria, Montalva \& Humber sp. nov. (Fig. 1).

MycoBank MB819472.

The colonies on SDAY/4 were initially colourless, becoming increasingly yellow immediately below developing conidial hymenia (typically after 5-8 days) and then greenish as conidia matured with the conidial mass bluish olive (Pantone 18-0316; CMYK 63:41:77:18). Conidiogenous cells ovoid to broadly ellipsoid, $10.91 \pm 0.24 \times 2.12 \pm 0.03 \mu \mathrm{m}$ (overall range: $7.55-14.46 \times 1.60-2.80 \mu \mathrm{m}$ ), narrowed apically but without any obvious neck. Conidia cylindrical, $4.98 \pm 0.07 \times 2.63 \pm 0.03 \mu \mathrm{m}$ (overall range: $3.88-6.55 \times 2.16-3.25 \mu \mathrm{m}$ ) (Fig. 1). M. alvesii cannot be distinguished from most related taxa based only on conidial and phialidic morphologies.

Holotype: UFG 50750 is a dried culture of CG1123 deposited in the Herbariun of the Federal University of Goiás, Goiânia, Brazil.

Ex-Type culture: CG1123, Invertebrate-Associated Fungal Collection (CFI), at Embrapa Genetic Resources and Biotechnology (Brasilia DF, Brazil), collected by R.B. Lopes, 02 February 2009, and co-deposited as ARSEF 13308 in the USDA-ARS Collection of Entomopathogenic Fungal Cultures (Ithaca, New York, USA).

Type locality: Commercial banana plantation at Quixeré, Ceará State, Brazil; S $05^{\circ} 09^{\prime} 10.5^{\prime \prime}$, W $38^{\circ} 00^{\prime} 05.2^{\prime \prime}$, at ca. $145 \mathrm{~m}$ above sea level.

Type substrate: soil sample from a commercial plantation of banana (Musa sp., genomic group AAB, cv. Prata-Anã) cultivated for 10 years and submitted to an intensive agricultural regime, including irrigation 


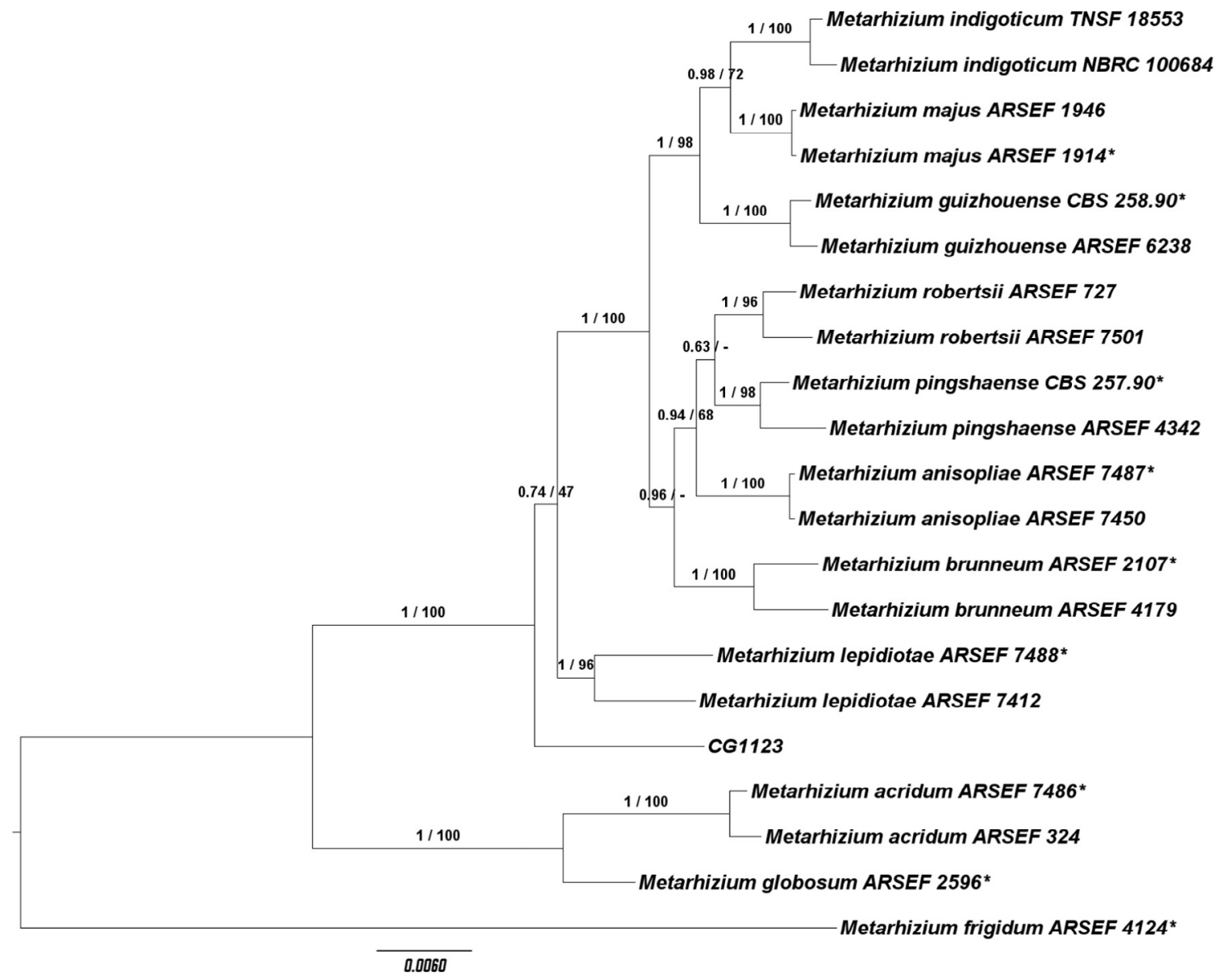

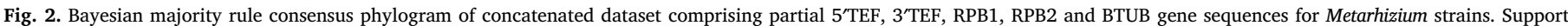

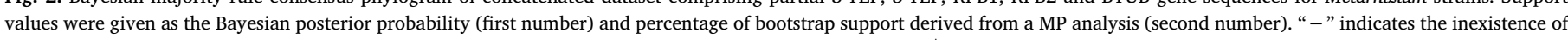

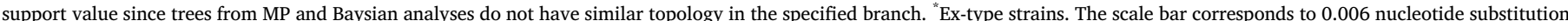
per site.

and pesticide applications.

Etymology: M. alvesii is named in honor of Sérgio Batista Alves, an influential professor of insect pathology at University of São Paulo (ESALQ-USP, Piracicaba, Brazil) for more than 30 years and who was a strong, globally known, and respected advocate for the use of microbial biological control of insect pests.

\subsection{Molecular characterization}

Phylogeny derived from the concatenated alignment for all five loci considered in this study ( $5^{\prime}$ TEF, 3' TEF, RPB1, RPB2, BTUB) provided robust results and showed CG1123 to belong in a unique branch (Fig. 2), thus confirming that this strain is, indeed, genomically distinct from the other taxa in the $M$. anisopliae species complex. Bootstrap values of $100 \%$ (MP) and 1 (Bayesian posterior probability) were obtained for the branch in which the strain CG1123 is placed. Analyses for the $5^{\prime}$ end of the TEF- $1 \alpha$ gene allowed discrimination of all taxa currently recognized in the $M$. anisopliae complex, whereas other gene sequences used in our work ( $3^{\prime}$ TEF, RPB1, RPB2, and BTUB) provided less informative tree topologies (see Supplementary Material).

\section{Discussion}

In the current systematics of such hypocrealean entomopathogenic fungi as Metarhizium spp., morphological traits are no longer regarded as usable for identification purposes (Glare et al., 1996; Driver et al., 2000; Rehner and Buckley, 2005). In fact, the only species within the $M$. anisopliae species complex whose (globose) conidia are morphologically distinct is M. globosum (Bischoff et al., 2009). Not surprisingly, measurements for $M$. alvesii conidia and phialides overlap in size and dimensions with other species within the $M$. anisopliae species complex (Bischoff et al., 2009; Kepler et al., 2014).

Although molecular tools such as single sequence repeat (SSR) markers have been proven useful to characterize strains of the $M$. anisopliae species complex, this approach is not adequate for species identification or reconstruction of phylogenetic relationships (Mayerhofer et al., 2015; Castro et al., 2016). CG1123 is currently the only example of $M$. alvesii, and the results presented here unambiguously support our claim that it is a new species. Moreover, the results have shown that CG1123 does not cluster with two unassigned lineages within this species complex that have been reported in Brazil (Rocha et al., 2013; Rezende et al., 2015). ESALQ 1636 clustered within the so-called PARB clade (composed of strains belonging to $M$. pingshaense, M. anisopliae s.s., $M$. robertsii and M. brunneum), whereas ESALQ 1374 clustered within MGT (originally composed by M. majus and $M$. guizhouense).

\section{Acknowledgments}

We are grateful to Antônio L.M. Mesquita (EMBRAPA Tropical Agroindustry, Fortaleza, Ceará State) for assistance in organizing the 2009 field trip to the municipality of Quixeré. We are also thankful to Eladio Rojas (Laboratorio Regional de Servicio Agrícola y Ganadero, Osorno, Chile) for access to microscopy facilities. Finally, we would like to mention the financial support for the first and last authors by EMBRAPA and CNPq, respectively. 


\section{Appendix A. Supplementary data}

Supplementary data associated with this article can be found, in the online version, at http://dx.doi.org/10.1016/j.jip.2017.12.001.

\section{References}

Alvares, C.A., Stape, J.L., Sentelhas, P.C., Gonçalves, J.L.M., Sparovek, G., 2013. Köppen's climate classification map for Brazil. Meteorol. Z. 22, 711-728.

Alves, S.B., Nakano, O., Nakayama, K., 1978. Nomuraea rileyi (Farlow) Samson, eficiente patógeno de Trichoplusia ni (Hübner, 1802). Ecossistema 3, 77.

Bischoff, J.F., Rehner, S.A., Humber, R.A., 2009. A multilocus phylogeny of the Metarhizium anisopliae lineage. Mycologia 101, 508-528.

Castro, T., Mayerhofer, J., Enkerli, J., Eilenberg, J., Meyling, N.V., Moral, R.A., Demétrio, C.G.B., 2016. Persistence of Brazilian isolates of the entomopathogenic fungi Metarhizium anisopliae and $M$. robertsii in strawberry crop soil after soil drench application. Agr. Ecosyst. Environ. 233, 361-369.

Driver, F., Milner, R.J., Trueman, J.W.H., 2000. A taxonomic revision of Metarhizium based on a phylogenetic analysis of rDNA sequence data. Mycol. Res. 104, 134-150.

Eiseman, L., Herbert, L., 1990. The Pantone Book of Color. Harry N. Abrams, Inc. Publishers, New York.

Faria, M., Wraight, S.P., 2007. Mycoinsecticides and mycoacaricides: a comprehensive list with worldwide coverage and international classification of formulation types. Biol. Control 43, 237-256.

Faria, M., Hajek, A.E., Wraight, S.P., 2009. Imbibitional damage in conidia of the en tomopathogenic fungi Beauveria bassiana, Metarhizium acridum, and Metarhizium anisopliae. Biol. Control 51, 346-354.

Glare, T.R., Milner, R.J., Beaton, C.D., 1996. Variation in Metarhizium, a genus of fungal pathogens attacking Orthoptera: Is phialide morphology a useful criterion? J. Orthopteran Res. 5, 19-27.

Kepler, R.M., Humber, R.A., Bischoff, J.F., Rehner, S.A., 2014. Clarification of generic and species boundaries for Metarhizium and related fungi through multigene phylogenetics. Mycologia 106, 811-829.

Liu, Y.J., Whelen, S., Hall, B.D., 1999. Phylogenetic relationships among ascomycetes: evidence from an RNA polymerase II subunit. Mol. Biol. Evol. 16, 1799-1808.

Lopes, R.B., Silva, S.D., Tigano, M.S., Button, M., 2012. Entomopathogenic fungi as potential control agents against the Brazilian ground pearl Eurhizococcus brasiliensis (Hemiptera: Margarodidae). Rev. Colomb. Entomol. 38, 247-251.

Lopes, R.B., Mesquita, A.L.M., Tigano, M.S., Souza, D.A., Martins, I., Faria, M., 2013a. Diversity of indigenous Beauveria and Metarhizium spp. in a commercial banana field and their virulence toward Cosmopolites sordidus (Coleoptera: Curculionidae). Fungal
Ecol. 6, 356-364.

Lopes, R.B., Souza, D.A., Oliveira, C., Faria, M., 2013b. Genetic diversity and pathogenicity of Metarhizium spp. associated with the white grub Phyllophaga capillatc (Blanchard) (Coleoptera: Melolonthidae) in a soybean field. Neotrop. Entomol. 42, 436-438.

Lopes, R.B., Faria, M., Souza, D.A., Bloch, C., Silva, L.P., Humber, R.A., 2014. MALDI-TOF mass spectrometry applied to identifying species of insect-pathogenic fungi from the Metarhizium anisopliae complex. Mycologia 106, 865-878.

Maddison, W.P., Maddison, D.R., 2015. Mesquite: a modular system for evolutionary analysis. Version 3.04. < http://mesquiteproject.org >

Magalhães, B.P., Faria, M., Tigano, M.S., Sobral, B.W.S., 1997. Characterization and virulence of a Brazilian isolate of Metarhizium flavoviride Gams and Rozsypal (Hyphomycetes). Mem. Entomol. Soc. Can. 171, 313-321.

Mayerhofer, J., Lutz, A., Widmer, F., Rehner, S.A., Leuchtmann, A., Enkerli, J., 2015. Multiplexed microsatellite markers for seven Metarhizium species. J. Invertebr. Pathol. 132, 132-134.

Montalva, C., Collier, K., Rocha, L.F.N., Inglis, P.W., Lopes, R.B., Luz, C., Humber, R.A., 2016. A natural fungal infection of a sylvatic cockroach with Metarhizium blattodeae sp. nov., a member of the M. flavoviride species complex. Fungal Biol. 120, 655-665.

Posada, D., 2008. JModelTest: phylogenetic model averaging. Mol. Biol. Evol. 25, 1253-1256.

Raeder, J., Broda, P., 1985. Rapid preparation of DNA from filamentous fungi. Lett. Appl. Microbiol. 1, 17-20.

Rehner, S.A., Buckley, E., 2005. A Beauveria phylogeny inferred from nuclear ITS and EF1-a sequences: evidence for cryptic diversification and links to Cordyceps teleomorphs. Mycologia 97, 84-98.

Rezende, J.M., Zanardo, A.B.R., Lopes, M.D., Delalibera, I., Rehner, S.A., 2015 Phylogenetic diversity of Brazilian Metarhizium associated with sugarcane agriculture. Biocontrol 60, 495-505.

Rocha, L.F.N., Inglis, P.W., Humber, R.A., Kipnis, A., Luz, C., 2013. Occurrence of Metarhizium spp. in Central Brazilian soils. J. Basic Microbiol. 53, 251-259.

Ronquist, F., Teslenko, M., van der Mark, P., Ayres, D., Darling, A., Höhna, S., Larget, B., Liu, L., Huelsenbeck, J.P., 2012. MrBayes v. 3.2: efficient Bayesian phylogenetic inference and model choice across a large model space. Syst. Biol. 61, 539-542.

Stiller, J.W., Hall, B.D., 1997. The origin of red algae: implications for plastid evolution. P. Natl. Acad. Sci. USA 94, 4520-4525.

Sujii, E.R., Tigano, M.S., Sosa-Gomes, D., 2002. Simulação do impacto do fungo Nomuraed rileyi em populações da lagarta da soja, Anticarsia gemmatalis. Pesq. Agrop. Bras. 37, 1551-1558.

Xavier-Santos, S., Lopes, R.B., Faria, M., 2011. Emulsifiable oils protect Metarhizium robertsii and $M$. pingshaense conidia from imbibitional damage. Biol. Control 59, 261-267. 